\title{
Performance Improvement of a Centrifugal Pump Filtration System for Industrial and Domestic Applications
}

\author{
P. B. Sob \\ Department of Mechanical Engineering, Faculty of Engineering and Technology, Vaal University of Technology, \\ Vanderbijlpark 1900, Private Bag X021, South Africa.
}

\begin{abstract}
Several filtration problem are reported in a centrifugal pump during operation in both domestic and industrial application. This problem have leads to membrane fouling that often leads to pump cavitation and other mechanical malfunctioning. Membrane technology were reported to be more promising in filtration process during centrifugal pump operation, though few problem of membrane fouling are still persisting which need further investigation. Critical parameters that affect membrane performance such as transmembrane pressure drop, pressure variation, density, flow of viscous fluid without impurities and flow of pure water was tested during modelling and simulation process. This was done to prevent the current problem of membrane fouling during pump operation. The design membrane simulated in this study was tested theoretically based on the experimental set up of a centrifugal pump. The testing and simulating process takes into account all physical parameters that affect membrane fouling during pump operation. The flow of pure water through the membrane was modelled theoretically using solid works and the major variables that impacted the separability was tested for optimal performance during filtration process without the occurrences of membrane fouling. The following facts were theoretically revealed by the simulated results. It was shown that a rapid decrease in flux was caused by concentration of polarisation during filtration process. It was also shown that membrane fouling increase membrane resistance and causes restriction to the transmission of the pure water and impurities during filtration. It was also revealed that the smaller the thickness of the membrane surface, the lower the rate at which the volumetric flux decreases during filtration. It was also shown that membrane viscosity increases with increasing pressure during performance. It was however revealed that pure water were able to be separated from impurities and the internal friction forces decreased during pump operation with little tendency of fouling being reported. It was also revealed that, although impurities were trapped on the membrane surface during pump operation, the higher resistance in the membrane surface the higher the possibility of membrane fouling during pump operation.
\end{abstract}

Keywords: Efficiency, temperature, flow rate, evaporator and stability.

\section{INTRODUCTION}

For years now there are several centrifugal pump failure due to poor filtration process that often leads pump blockage (Reyner 1995). Several design consideration have been done to prevent centrifugal pump failure during operation such as designing the pump section with a screen filter in order to monitor fouling process (Tulleken, 2012). The screen filters also suffer from blockages due to cake layers that normally build up and need to be cleaned regular (Tulleken, 2012). The cleaning process is normally done by either mechanically application for a large scale screens or manually for small screens depending on the flow rate of the pump system. Pump blockages are also avoided by employing macerators which is very expensive and ineffective due to regular maintenance during usage (Tulleken, 2012). This filtration system are not widely used due to difficult periodic maintenance that are also very expensive.

In the food and beverage industries, impurities such as breweries, dairy, meat and fish and hot frying oil usually blockage the filtration process in a centrifugal pump. The largest centrifugal pump produced by Verder Pumps South Africa for the food industry was designed in 2017 to address this current problem. The designed pump is capable of pumping 8 million $250 \mathrm{ml}$ bottle an hour (Creamer media 2017). The pumping pressure have their setback during pump operation as pumping fluids containing substantial liquids, slurries and pastes having high levels of viscosity which causes blockages/fouling in the pump during operation. More so, the surface of a centrifugal pump that works for a longer period of time gets deteriorated due to fouling, cavitation or erosion are commonly reported (Sayed \& Abdus, 2017). Therefore a proper filtration system must be design in a centrifugal pump system in order to minimize the occurrences of fouling during pump operation.

To solve the current problem of random fouling during filtration process, researchers have redesigned new pumping system strainers suction and the current problem is still persisting. Centrifugal pump strainers often get blocked when impurities gets accumulated on the surface of the strainers during pump operation. When this happens more serious problem such pump cavitation, starvation and possible premature failure are reported (Pushpdant \& Prabhash, 2012). Filters are also reported to have more complicated performance problem than strainers due to the fact that filter have more chances of clogging (Kozey, 2012). Improvement on strainer for better 
performance have been done by designing a special strainer that is used to draw fluid from an open body of fluid, such as a sump, pond, lake and river was made (Kozey, 2012). The specific strainer invented contains a bottom guard and a counterweight. The motivation for this invention was due to the fact that water is often drawn from an open source which contains debris, leaves and twigs which interferes with the operation of the pump. The working principle of this strainer is that the suction side is attached to the strainer which includes a float to keep the pipe near the surface of the water. Keeping the pipe near the surface reduces chances of the pump sucking in the impurities that lie at the bottom of the open water source. The operational limitations are not mentioned making the study uncertain. Other filtration design are also proposed such as $\mathrm{Y}$ methods were used and the system were reported to be efficient during operation though the problem of fouling persisted during filtration process (Kozey, 2012). Recently membrane technology are reported to be more promising with efficient and stable filtration process though with little fouling being reported that needs to be controlled (Smarajit, 2016). One of the advantages of the membrane technology is that it is durable and more efficient with stable filtration process (Amira, 2019). However membrane fouling was also reported during the pump operation due to poor membrane pore sizes characterisation which need further attention (Amira, 2019). This have often lead to performance drops in filtration process (Abdelrasoul, Doan, \& Lohi, 2013). In the current study the membrane pore sizes is being characterised for optimal filtration process. This was achieved by empirical simulation of the major parameters that affect membrane pore sizes distribution and efficient transfer of pure water during pump operation.

\subsection{Modelling and Simulation the major parameters in a membrane system}

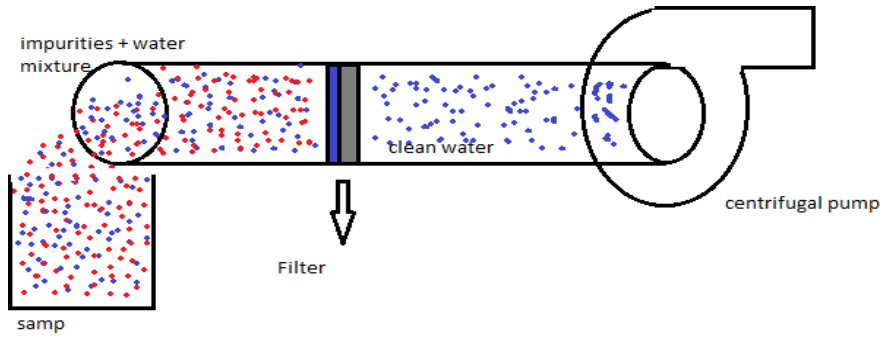

Figure 1. Proposed simulated membrane filtration system

Figure 1 shows an experimental set up of the membrane in a pipeline with a centrifugal pipe at the other end. As shown, the flow, before passing through the filter, contains water mixed with impurities and on the exit side of the membrane; the water is clean because all the impurities have been filtered out. The water comes from a coal plant water sump. The purpose of the filter is to protect the centrifugal Pump against erosion, corrosions, blockages, and cavitation. Simulation is done using solid works and the major parameters are varied during simulation for optimal performance of the membrane filtration process and results and presented and discussed.

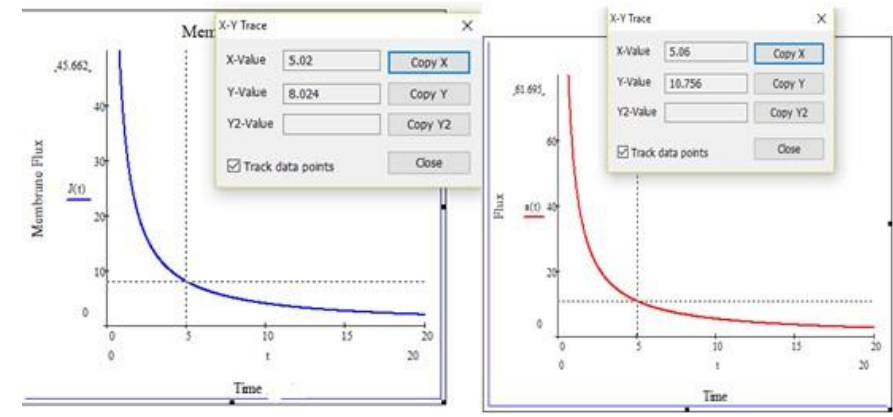

Figure 2 (a) Membrane Flux against Time (s) (b) flux against time (s)

As already stated, the volumetric membrane decreases with time as, also, shown in Fig.

2. This is caused by the factors, already mentioned, that increase resistance with respect to time. It is seen that the rapid flux decrease is caused by both concentration polarisation and the membrane fouling which increase membrane resistance and cause a restriction to the transmission of the matter (Mousavi, Dolati, \& Ghaffarian, 2010). However, the smaller the thickness of the membrane, the slow the rate at which the volumetric flux decreases. Using the same membrane with a much lower membrane area yielded a much more stable membrane and increased time for the membrane to be affected by fouling. This is explained further by Fig. 3 (a-b).

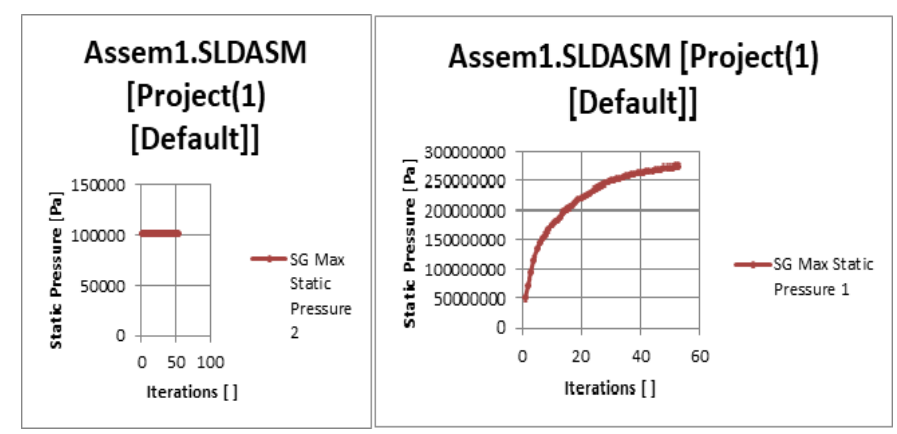

Figure 3 (a) Static pressure against iteration

(b) Static pressure against iteration

The static pressure is decreasing with iteration. However, it decreases until it remains constant at the predetermined static pressure after the membrane. This is because, as seen from the tunnel exit, the pressure was predetermined to be atmospheric which is why it is seen to be constant after the membrane exit. At this point, it does not matter how many iterations are made because it was user-predetermined as it is a requirement by solid works. Even though the flowobjective would be to reach the atmospheric pressure, the high pressure drop is caused by the resistance of the membrane because of its thickness and the scaling of the impurities on the membrane pores.

The inlet pressure into the tunnel was roughly $260 \mathrm{MPa}$. But, for the pressure to finally drop to atmospheric as seen at tunnel exit, there has to be a very high pressure drop in the membrane. This high pressure drop was caused by a higher resistance membrane due to thickness, solid particles blocking pores, or 
scaling (RIPPERGER, GOSELE, \& CHRISTIAN). As scale tends to build up on the membrane surface, the flow experiences a greater resistance to flow and this is what led to the higher pressure drop. So, the total resistance of such membrane becomes very high causing a high pressure drop.

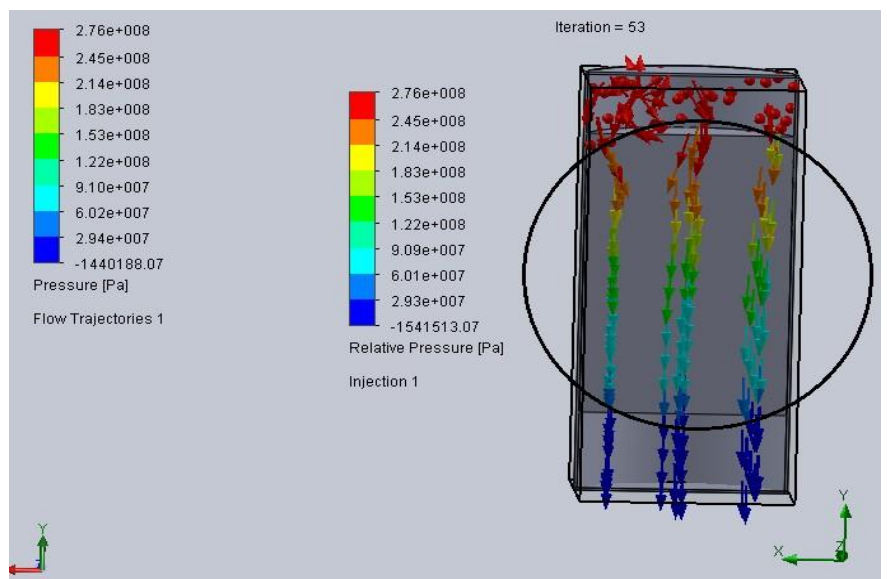

Figure 4: Showing flow trajectory and Pressure variation

As observed, Fig.4 shows the pressure distribution for a membrane with a high resistance and placed just next to the tunnel entry. As seen, in the Fig.4 above, the pressure is higher at tunnel entry as previously explained. Furthermore, the TMP is an indication of the fouling taking place with respect to time. This is due to the combination of sieving, adsorption of particulates and compound onto membrane surface or within the pores (Abdelrasoul, Doan, \& Lohi, 2013). However (MUNIR C. , 1998) reported that the flow rate or turbulence, whether due to pumping or moving the membrane, has noticeable effect on the permeate flux. This is also the same as show in the figure above. Furthermore, the advantage of having such membrane is that, when there is fluid mixing as shown above, the mixing fluid can sweep away the accumulated solute, therefore reducing the hydraulic resistance of the cake and reducing the thickness of the cake (Qusay, Talib, \& Muntaz, 2013).

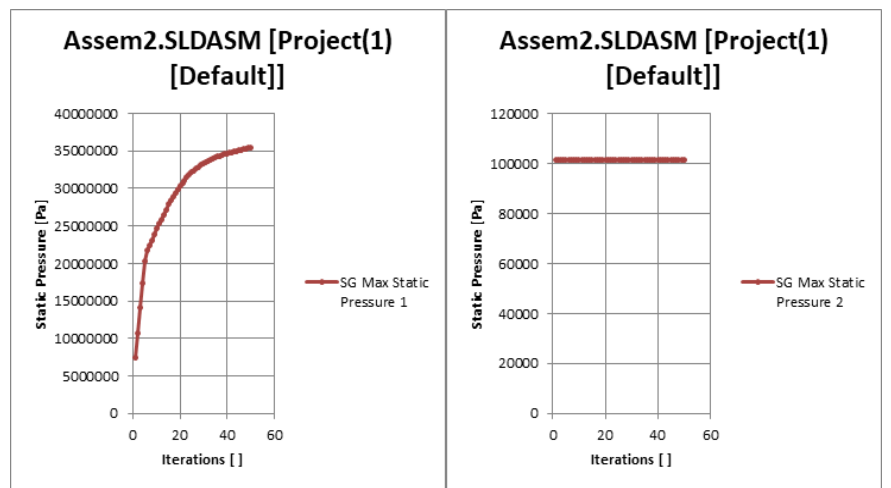

Figure 5: Pressure variation for a thinner membrane

As already stated, the pressure was predetermined to be atmospheric at tunnel exit. As observed in Fig.5 the pressure at entry to the tunnel was about $35 \mathrm{MPa}$ which is a decrease from the one at a higher thickness. As explained previously, the pressure will drop across the membrane but the drop here will be very small as opposed to using a membrane with a thicker membrane thickness. The scientific reason is explained by (RIPPERGER, GOSELE, \& CHRISTIAN). The smaller thickness results in a lesser membrane resistance which allows more permeate to pass through the membrane. Even though, fouling and scaling may build up on the membrane surface, the pressure drop would be much lesser because the membrane itself has a lesser resistance. This explains the results found in this study and (MUNIR A. , 2006). Also, according to the simulation, a membrane placed at the centre of the water tunnel revealed that the pressure upstream of the membrane was much lower than when a membrane was placed next to the water tunnel. A possible reason for this is that a centred membrane allows the flow to follow a straight path than a mixed layer which caused the high pressure upstream a membrane placed next to the tunnel entry.

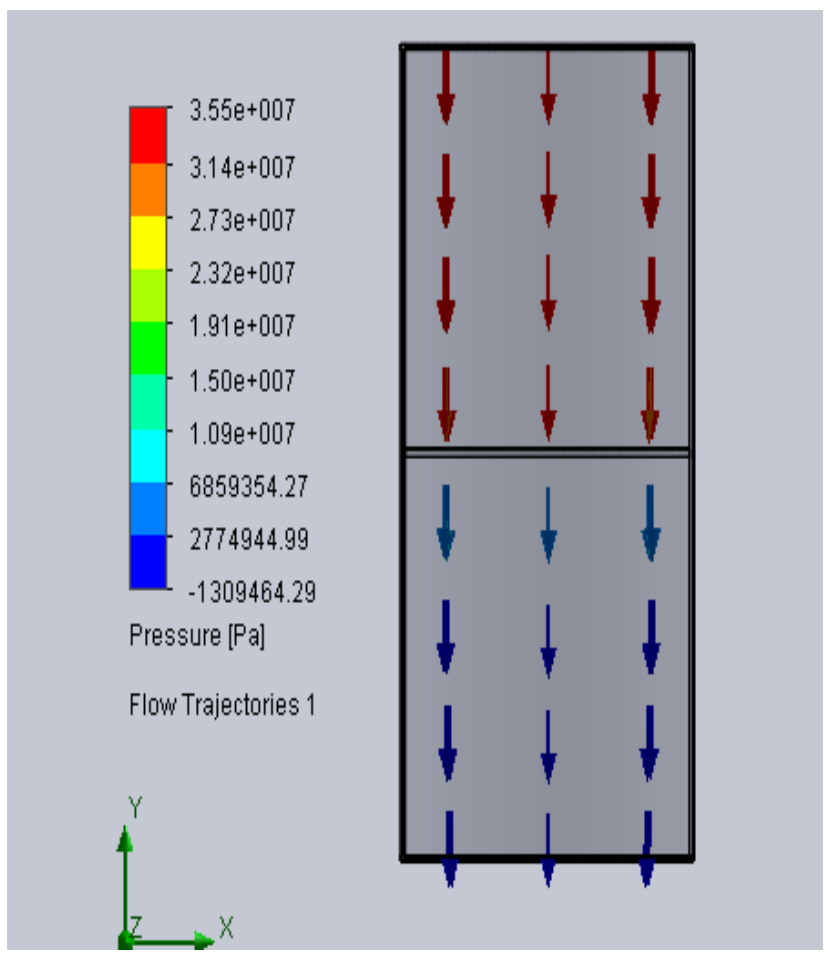

Figure 6: Pressure variation through flow trajectory for a thinner membrane

Figure 6 shows the pressure variation across the membrane for a thin membrane. As seen, there is much lesser pressure drop. This, as already explained, is due to the fact that when there is lesser resistance, there is little or no force opposing flow. So the flow is likely to not mix as when there is more resistance and the membrane moved up. 


\subsection{Density and Concentration}

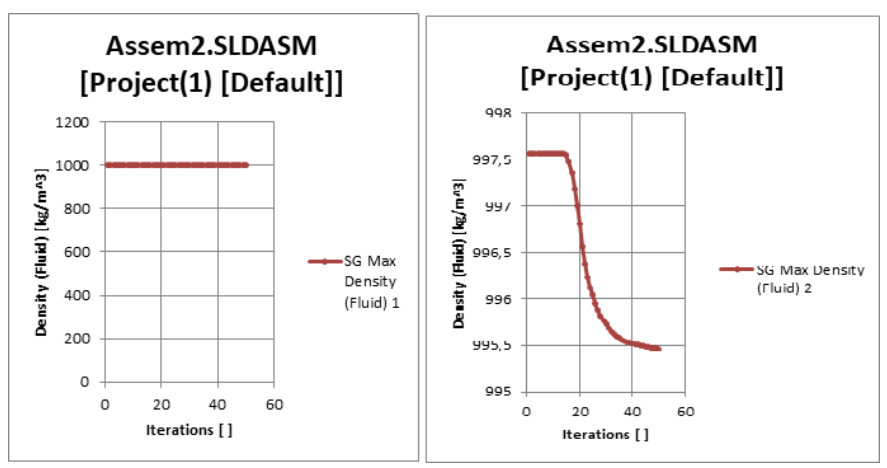

Figure7: (a) Density against iteration (b) Density against iteration across the flow (thick)

According to a paper by (Said, Sajid, Kamyar, \& Saidur, 2013), a direct proportional relationship exists between density and concentration. This means that when density increases, the concentration will also increase and vice versa. With that being said, it is easier to understand that a membrane filter that has filtered properly should produce a permeate with lesser concentration or density. Now, looking at figure 7, it is observed that prior to the membrane, the density/concentration is constant. This means that the concentration of the impurities and water has not changed. However, out of the membrane it is observed to have changed. This is because the impurities have been filtered and are on the membrane surface. However, it is worth noting that, for a membrane with a bigger thickness, the concentration does not drop that much because of the high resistance which opposes the permeate flow (VLADISAVLJEVIC, VUKOSAVLJEVIC, \& BUKVIC, 2003).

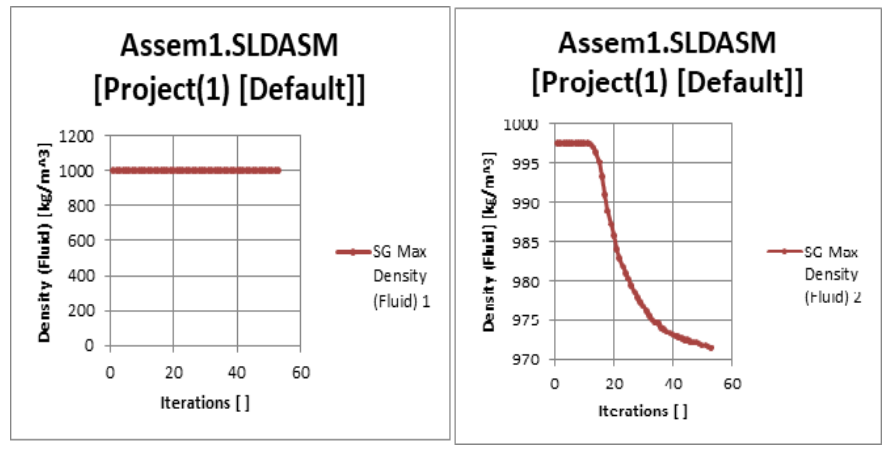

Figure 8: Density variation across the flow (thin)

As observed from figure 8, a thinner membrane has more concentration decrease. And, still prior to the membrane the concentration is constant because at this point, nothing is been filtered yet. As already explained in this study, this is because when a membrane has less resistance, there is more permeate flow out of the membrane. This improves the mass transfer coefficient, reduces concentration polarisation and accumulation of retained solutes (VLADISAVLJEVIC, VUKOSAVLJEVIC, \& BUKVIC, 2003). When comparing figure 8 and figure 7 it is observed that when a membrane has less resistance, it has a higher filtering efficiency which explains why the concentration dropped higher in figure 8 as opposed to the drop in figure 7.

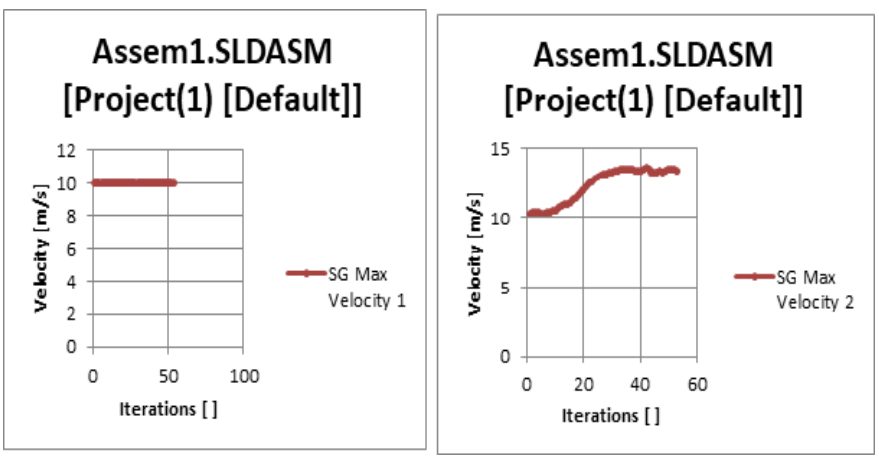

Figure 9: Velocity variation across flow (thick)

The velocity results in figure 9 showed that the velocity increased during the filtration process. This was due to the decrease of flow area. However, the velocity then continued to increase towards membrane exit and hit the water tunnel exit above the initial value at the atmospheric pressure predetermined at the tunnel exit.

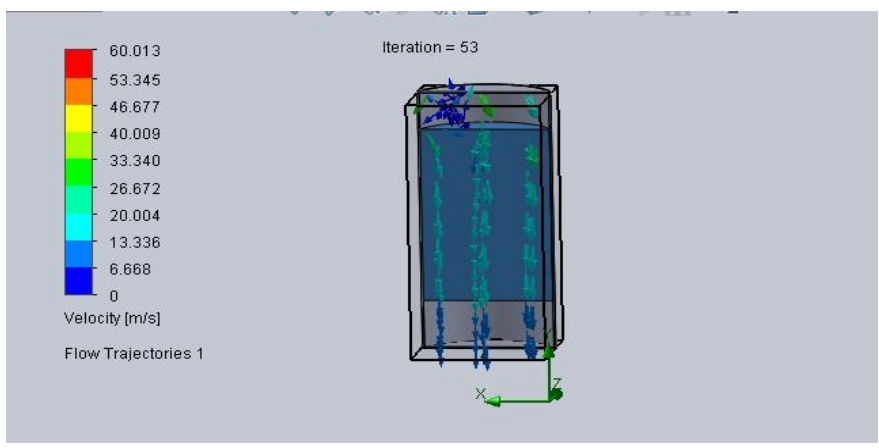

Figure 10: Velocity flow trajectory (thick)

Studying the velocity profile further revealed that the flow layers mixed towards membrane entry. This was caused by the porous medium being placed closer to the tunnel entry. But, as soon as the flow entered the membrane, layers began to develop straight flow towards the exit. Since the tunnel exit pressure was predetermined to be atmospheric, this caused the flow pressure to decrease towards the tunnel exit. And, viscosity increases with increasing pressure, however, pressure was decreasing. This meant that viscosity was decreasing. The water molecules were now easy to move because the internal friction forces decreased. The figure 11 below explained this phenomenon clearly with the circled area showing the membrane. Although the impurities were trapped on the membrane surface, as shown below, but higher resistance in the membrane increased the chances of fouling occurring. Also, the turbulent flow has an advantage of sweeping the impurities help onto the membrane as shown below (Qusay, Talib, \& Muntaz, 2013). 

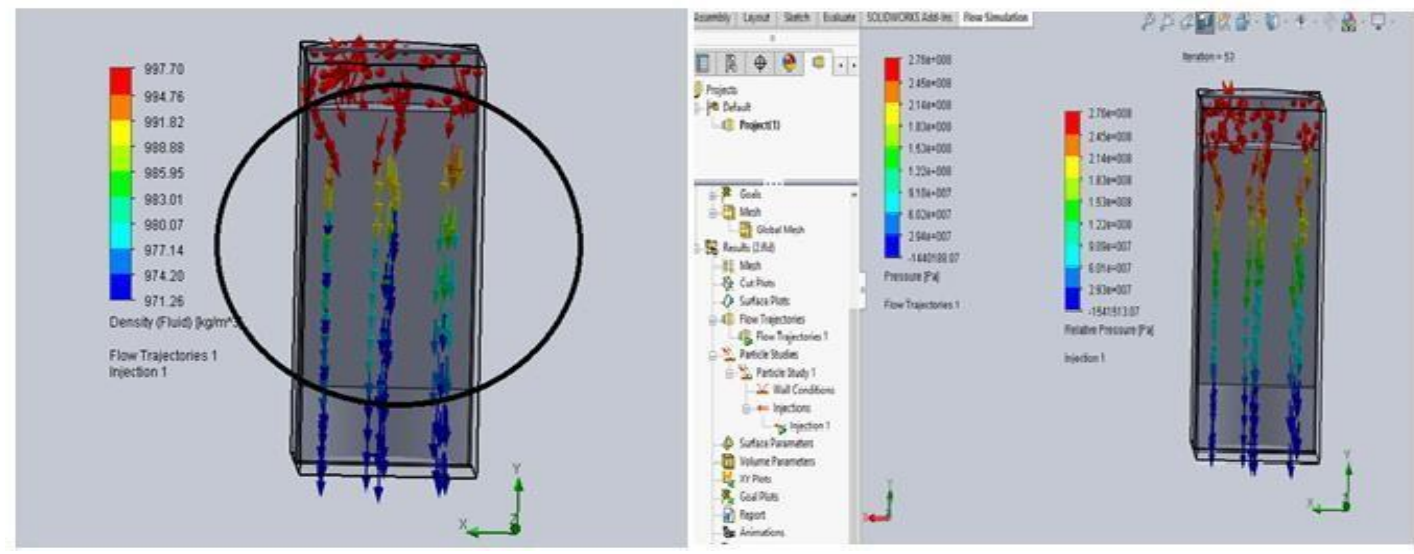

Figure 11: Velocity flow trajectory and particle injection

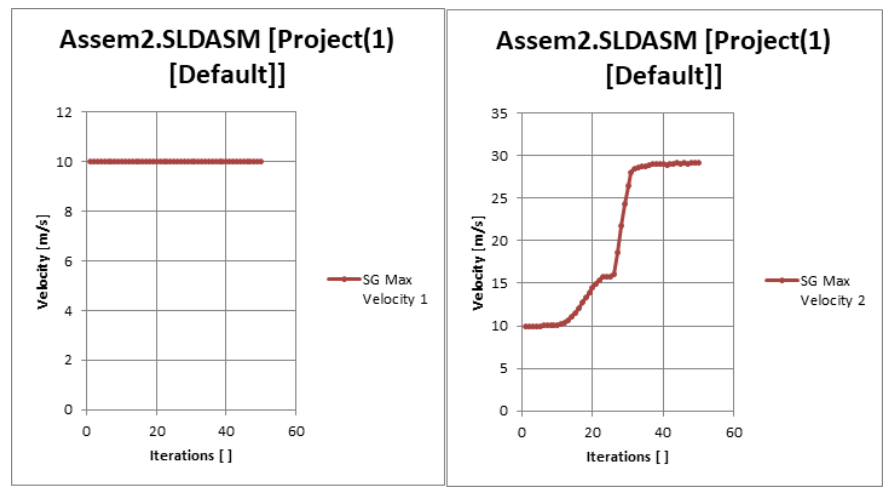

Figure 12: Velocity variation through the flow

The velocity distribution curve showed that the velocity increase was much higher for the shorter membrane because of lesser losses. Also, the pressure across the membrane was not wasted due to having a membrane with lesser resistance. In a nutshell, the membrane with lesser losses acts a nozzle, accelerating the flow at membrane exit.

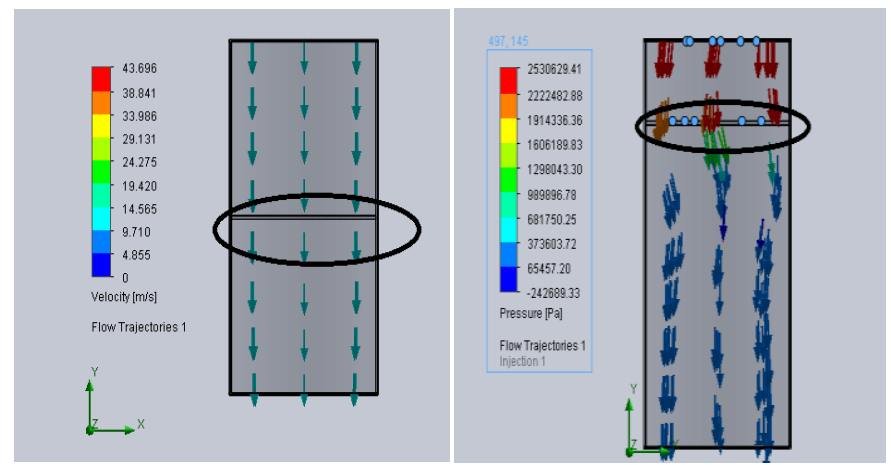

Figure 13: Velocity variation and the position of the membrane

The velocity variation in figure 13 shows the variation of the velocity across the flow and the membrane (circled part). The flow is a laminar flow with no fluid layer mixing. The resistance is very low due to smaller thickness of the membrane as already stated in this study.

\subsection{Conclusion and Recommendation}

The current study was aimed at modelling the filtration of a centrifugal pump to prevent fouling during pump operation. In order to achieve this a membrane technology was designed and modelled for optimal performance during pump operation. It was shown rapid flux decrease is caused by both concentration polarisation and the membrane fouling which increase membrane resistance and cause a restriction to the transmission of the matter. It was also shown that the static pressure is decreasing with iteration. However, it decreases until it remains constant at the predetermined static pressure after the membrane. It was also revealed that when the membrane is placed at the centre of the water tunnel, the pressure upstream of the membrane was much lower than when a membrane was placed next to the water tunnel. It was also observed that the velocity profile further revealed that the flow layers mixed towards membrane entry during pump operation. This was caused by the porous medium being placed closer to the tunnel entry. It was also revealed that, as soon as the flow of fluid entered the membrane, layers began to develop straight flow towards the exit. Since the tunnel exit pressure was predetermined to be atmospheric, this caused the flow pressure to decrease towards the tunnel exit. It was also shown that the viscosity increases with increasing pressure, however, pressure was decreasing. Although the impurities were trapped on the membrane surface, as shown below, but higher resistance in the membrane increased the chances of fouling occurring.

\section{ACKNOWLEDGEMENT}

The material is based on the work which is supported financially by the Vaal University of Technology (VUT).

\section{REFERENCE}

[1] Abdelrasoul, A., Doan, H., \& Lohi, A. (2013). Fouling in Membrane Filtration and Remediation Methods.

[2] Abdelrasoul, A., Doan, H., \& Lohi, A. (2013). Fouling in Membrane Filtration and Remediation Methods. In A. Abdelrasoul, H. Doan, \& A. Lohi, Fouling in 
Membrane Filtration and Remediation Methods. Web of Science.

[3] Abdelrasoul, A., Doan, H., \& Lohi, A. (2013). Fouling in Membrane Filtration and Remediation Methods. Web of Science.

[4] Acharya, S. (2016). Analysis and FEM simulation of flow of fluids in pipes.

[5] AISSA, W. (2009). Effect of inlet conditions on centrifugal pump performance.

[6] International Journal of Fluid mechanics Research.

[7] Amira, A. (2019). Advances in membrane Technology for paving the way for water sustainability. Material Science engineering. Berlin.

[8] BANSAL, R. (2005). A textbook of Fluid mechanics and Hydraulic machines.

[9] BELFORT, G., \& ZYDNEY, A. (1994). The behaviour of Suspension and Macromolecular Colutions in Crossflow Microfiltration. Journal of Membrane Science.

[10] Bellary, S., Husain, A., Samad, A., \& Kanai, R. (2018). Performance optimization of centrifugalpump for crude oio ddelivery. The Journal of Engineering Research, 88- 101.

[11] Chaudhary, S., \& Verma, S. (2015). Effect of sand size and concerntration on erosion in closed impeller of centrifugalpump. International Journal of Applied Engineering Research, 10.

[12] CSIR. (2003). Guidelines for Human Settlement Planning and Design (Vol. 2). Pretoria: CSIR: Building and Construction Technology.

[13] Dixon, S., \& Hall, C. (2014). Fluid Mechanics ad Thermodynamics of Turbomachinery. In Fluid Mechanics ad Thermodynamics of Turbomachinery (7th ed., pp. 41-43). Elsevier Inc.

[14] Dunn, D. (2010). Retrieved June 15, 2019, from www.freestudy.co.uk

[15] ELSEVIER. (1999). The Secrets of Succesful Submersible Sewage Pumps. World Pumps(394), 3842 .

[16] FANE, A., \& FELL, C. (1987). A review of fouling and fouling control in Ultrafiltration. 62, 117-136.

[17] Hongyu, L., \& Chen, V. (2010). Membrane Fouling and Cleaning in Food and Bioprocessing. Membrane Technology.

[18] IPPEN, A. (1946). The Influence of Viscosity on Centrifugal Performance. ASME, 68(8), 823-830.

[19] Jelemensky, M., Paulen, R., Fikar, M., \& Kovacs, Z. (2014). Time-optimal Diafiltration in the Presence of Membrane Fouling. The International Federation of Automatic Control.

[20] JONES, G. (2006). Pumping Station Design (3rd ed.).
Amsterdam: Elsevier.

[21] Kim, Y., \& Lee, K. (2015, May 07). Fuel Cell Membrane Characterizations. Polymer Reviews.

[22] Kisielus, V. (2012). Bio-fouling in Cross-flow membrane system.

[23] Kozey, G. (2012, June 05). Patent No. US 8,192,622 B2. United States of America.

[24] Kumar, K., Kumar, N., Rao, V., Shinde, S., \& Nandi, S. (2018). Design Optimization of Filter using CFD for Energy Conservation. Asian Journal For Convergence In Technology, 3(3).

[25] LI, N., FANE, A., WINSTON, W., \& MATSUURA, T. (2008). Advanced Membrane

[26] Technology and Application.

[27] LI, W. (2000, April). Effects of Viscosity of Fluids on Centrifugal Pump Performance and Flow Pattern in the Impeller. International Journal of Heat and FluidFlow, 2(21), 207-212.

[28] LUO, X., ZHANG, Y., PENG, J., \& XU, H. (2008, May). Effect of Impeller Inlet Geometry on Centrifugal Pump Cavitation Performance.

[29] LUO, X., ZHANG, Y., PENG, J., XU, H., \& YU, W. (2008). Impeller inlet geometry effect on performance improvement for centrifugal pumps. Journal of Mechanical Science and Technology.

[30] MAHENDRAN, R., MALAISAMY, R., \& MOHAN, D. (2004, February 2). Cellulose acetate and polyethersulfone blend ultrafiltration membranes. Part 1: Preparation and characterization. Polymer For Advanced Technologies, 149-157.

[31] McKee, K., Forbes, G., Mazhar, I., Entwitle, R., \& Howard, I. (n.d.). A review of major centrifugal pump failure modes with application to the water supply and sewage industries.

[32] METCALF, \& EDDY. (2003). Wastewater Engineering Treatment and Reuse (4th ed.). Boston.

[33] Mohamed, F., Sadek, Z., Ahmed, A., \& Azouz, A. (2013). Performance Characteristics of Centrifugal Pum Conveying Soft Slurry. American Journal of Mechanical Engineering, 1(5), 103-112.

[34] Mousavi, S., Dolati, H., \& Ghaffarian, V. (2010, March). treatment of Soy oil effluent using ultrafiltration. Water Practice and Technology.

[35] Mujahid, M., Hafiz, M., \& Khalil, M. (2015, May). Fluid Mechanics in Membrane Filtration: A simplified Analytical Approach. International Journal of Scientific Research Engineering and Technology (IJSRET), 4(5).

[36] MUNIR, A. (2006). Laboratory Feasibiity Studies in Environmental Engineering. MUNIR, C. (1998). Ultrafiltration and Microfiltration. Technomic Publishing Company. 
[37] NAKAO, S., WIJMANS, J., \& SMOLDERS, C. (1986). Resistance to the permeate flux in unstirred ultrafiltration of dissolved macromolecular solutions. Journal of Membrane Science, 26, 165-178.

[38] NESTA, J., \& BENNETT, C. (2005, June 5-10). Fouling mitigation by design. Engineering Conference International.

[39] NOZAIC, D., \& FREESE, S. (2009). Process Design Manual For Small Wastewater Works.

[40] Olusegun, O., \& Adeleke, E. (2015). Velocity Profile of Fluid Flow in Heterogenous Porous Media. International Conference on Chemical, Environmental and Biological Sciences. Dubai (UAE).

[41] Patel, M., \& Doshi, A. (2013, January). Effect of Impeller Blade Exit Angle on the Performance of Centrifugal Pump. International Journal of Emerging Technology and Advanced Engineering, 3(1).

[42] Pushpdant, J., \& Prabhash, J. (2012, SeptemberOctober). Product Planning and Development of Bucket Type Strainer Used In Thermal Power Plant. Journal of Mechanical and Civil Engineering, 3(2), 29-35.

[43] Qusay, F., Talib, M., \& Muntaz, A. (2013). A Study Of The Effect Of Operating Conditions On Reverse Osmosis Membrane Performance With And Without Air Sparging Technique. Chemical Engineering Communication, 1-19.

[44] REYNER, R. (1995). Pump Users Handbook (4th ed.). Amsterdam: Elsevier.

[45] REYNOLDS, O. (1883). An Experimental Investigation of the Circumstances which Determines Whether the motion of Water Shall be Directe or Sinuous, and the Law of Resistance in Parallel Channels. In O. Reynolds, An Experimental Investigation of the Circumstances which Determines Whether the motion of Water Shall be Directe or Sinuous, and the Law of Resistance in Parallel Channels (Vol. 174, pp. 935-982).

[46] RIPPERGER, S., GOSELE, W., \& CHRISTIAN, A. (n.d.). Filtration 1: Fundamentals.

[47] Ullmann's Encyclopedia of Industrial Chemistry, 14, 678-707.

[48] Said, Z., Sajid, M., Kamyar, A., \& Saidur, R. (2013). Experimental Investigation on the stability and density of Ti02, Al203, Si02 and TiSi04. Earth and Environmental Science, 16.

[49] Sanda, B., \& Daniela, C. (2012). The Influence of the Inlet Angle Over The Radial Impeller Geometry Design Approach with Ansys. Journal of Engineering Studies and Research, 18(4).

[50] Sayed, A., \& Abdus, S. (2017, January). Effects of Crude Oil-Water Emulsion at Various Water-Cut On
The Performance of The Centrifugal Pump. International Journal of Oil Gas and Coal Technology, 16(1).

[51] Shinde, S., \& Wankhede, S. (2018). Optimization of large size fabricated Y-Strainers for improvement in pressure drop value using CFD analysis. International Journal Of Advance Research, Ideas And Innovation In Technology, 4(4).

[52] Shrestha, A. (2012). Characterization of Porous Membrane via Porometry.

[53] Siddiqui, M., Arif, A., \& Bashmal, S. (2016, August 6). Permeability-Selectivity Analysis of Microfiltration and Ultrafiltration Membranes: Effect of Pore Size and Shape Distribution and Membrane Stretching. (E. Driol, Ed.) Membranes.

[54] Smarajit, R. (2016). Innovative use of membrane technology in mitigation of GHG emission and energy generation., (pp. 474-482). London.

[55] Sreedhar, B., Albert, S., \& Pandit, A. (2017). Cavitation damage: Theory and measurement - A review. Elsevier, 177-196.

[56] Torabi, R., \& Ahmad, S. (2016, May 29). The effect of Viscosity on Performance of Low Specific Speed Centrifugal Pump. (G. Bois, Ed.) International Journal of Rotating Machinery.

[57] Tulleken, J. (2012). Enquiries into sewage pump station problems with specific focus om removing solids .

[58] VESILIND, P. (2003). Wastewater Treatment Plant Design.

[59] VLADISAVLJEVIC, G., VUKOSAVLJEVIC, P., \& BUKVIC, B. (2003, December).

[60] Permeate Flux and Fouling resistance n Ultrafiltration of depectinized apple juice using ceramic membranes. Journal of Food Engineering.

[61] Yang, H., Lee, K., Kim, J., \& Choi, Y. (2018). Analysis of performance variation with cavitation test for a mixed-flow pump. Earth and Enviromental Science, 163. 